\title{
O estudo da biodiversidade e evolução vegetal através de marcadores de DNA e citogenética: exemplos em Iridaceae e Poaceae
}

\section{The study of biodiversity and plant evolution through molecular markers and} cytogenetics: examples in Iridaceae and Poaceae

\author{
Tatiana Teixeira de Souza Chies ${ }^{1,2}$, Paula Burchardt ${ }^{2}$, Eudes Maria Stiehl Alves ${ }^{2}$, \\ Liliana Essi ${ }^{3}$ e Eliane Kaltchuk dos Santos ${ }^{* 2,4}$ \\ ${ }^{1}$ Departamento de Botânica, Instituto de Biociências, Universidade Federal do Rio Grande do Sul, \\ Porto Alegre, Brasil \\ ${ }^{2}$ Programa de Pós-Graduação em Genética e Biologia Molecular, Universidade Federal do Rio Grande do Sul, \\ Porto Alegre, Brasil \\ ${ }^{3}$ Departamento de Biologia, Centro de Ciências Naturais e Exatas, Universidade Federal de Santa Maria, \\ Santa Maria, Brasil \\ ${ }^{4}$ Departamento de Genética, Instituto de Biociências, Universidade Federal do Rio Grande do Sul, \\ Porto Alegre, Brasil
}

\begin{abstract}
Resumo
Esse artigo apresenta uma revisão sobre o uso de marcadores moleculares e citogenéticos aplicados à detecção da biodiversidade vegetal. São citados exemplos de aplicação destas ferramentas na investigação de táxons pertencentes às famílias de Monocotiledôneas, Iridaceae e Poaceae, que são alvo de pesquisa científica dos autores desse artigo.
\end{abstract}

Palavras-chave: Marcadores moleculares, genética de populações, citotaxonomia, poliploidia, tamanho do genoma, genomas vegetais.

\begin{abstract}
We present here a review of the use of molecular markers and cytogenetic data, applied to the detection of plant biodiversity. We mentioned a few examples of application of these tools in the investigation of taxa belonging to the families of monocotyledonous Iridaceae and Poaceae, which are the subject of scientific research of the authors of this review.
\end{abstract}

Keywords: Molecular markers, population genetics, cytotaxonomy, polyploidy, genome size, plant genomes.

\footnotetext{
* eliane.kaltchuk@ufrgs.br
} 


\section{Introdução}

$\mathrm{B}$ iodiversidade pode ser definida como a variedade e variabilidade existente entre organismos vivos e as complexidades ecológicas nas quais eles ocorrem. O Brasil é considerado o país detentor da maior diversidade biológica do Planeta e com a maior diversidade genética vegetal do mundo, estimada entre 350.000 e 550.000 espécies (GUERRA \& NODARI, 2003). A magnitude desta biodiversidade é estimada em mais de dois milhões de espécies distintas de plantas, animais e microorganismos.

Apesar desta megadiversidade vegetal, a biodiversidade da flora brasileira é apenas parcialmente conhecida. Os organismos que dela fazem parte carecem, em sua maioria, de conhecimento quanto às relações filogenéticas e níveis de diversidade genética de uma forma global. Nesse contexto, estudos de sistemática e genética vegetal são essenciais para disponibilizar conhecimento sobre os táxons a fim de estabelecer programas de conservação e uso adequado de espécies com potencial econômico.

Estudos que visam caracterizar e conhecer as relações de parentesco dos táxons têm se servido de ferramentas de biologia molecular. Desde a década de 1980, cientistas vêm desenvolvendo novas tecnologias que permitem explorar os genomas dos organismos e desvendar os níveis de variabilidade e de diversidade genética. No caso de plantas, características intrínsecas dos genomas vegetais são utilizadas em associação com estratégias moleculares para conhecer as relações filogenéticas entre os táxons e assim, propor sistemas de classificação de espécies a partir das relações de parentesco. Uma das grandes vantagens no uso de caracteres moleculares em comparação ao fenótipo observado por características morfológicas é a objetividade da interpretação dos dados, além de não haver influência ambiental direta nos caracteres observados.

\section{Marcadores Moleculares}

A busca na detecção dos níveis de variabilidade genética, além de importante para estudos com enfoque na evolução dos grupos taxonômicos, pode ser utilizada por ecólogos e sistematas em outras abordagens investigativas; por exemplo, em estudos de inferência de parentesco, na delimitação de espécies, na detecção sobre os modos de reprodução e estrutura populacional, e em estimativas de níveis de migração e dispersão nas populações (AVISE, 1994).

Na primeira metade do século $X X$, técnicas de genética clássica eram utilizadas. A partir da segunda metade desse mesmo século, novas técnicas foram surgindo, permitindo o acesso direto às informações do DNA, RNA e proteínas. A eletroforese de isoenzimas constituiu-se na primeira ferramenta utilizada em estudos de variabilidade genética e é fundamentada nos genótipos detectados a partir de padrões eletroforéticos (PINTO et al., 2001; SOLFERINI \& SCHEEPMAKER, 2001).

No final da década de 1960, a descoberta das enzimas de restrição por Linn e Arber (1968) e Meselson e Yuan (1968), revolucionou a emergente Biologia Molecular. Em 1974, Grodzicker et al. utilizaram pela primeira vez a técnica atualmente denominada de RFLP ("Restriction Fragment Lenght Polymorphism"), que utiliza enzimas de restrição para a detecção de polimorfismos moleculares (ARIAS \& INFANTE MALACHIAS, 2001). Entretanto, $\mathrm{o}$ advento que revolucionou a biologia molecular foi a criação da técnica da PCR ("Polymerase Chain Reaction"), em 1985, pelo bioquímico Kary B. Mullis, o que the rendeu o Prêmio Nobel de Química, em 1993. Esta metodologia fundamenta-se na síntese in vitro de moléculas de DNA, utilizando neste procedimento uma enzima DNA polimerase termoestável (SAIKI et al., 1988). Desde então, novas técnicas fundamentadas em PCR vêm surgindo. Atualmente, os marcadores moleculares são utilizados com os mais diversos enfoques, incluindo estudos de variabilidade genética, programas de melhoramento vegetal, estudos evolutivos, entre outros. Os diversos tipos de marcadores moleculares disponíveis diferenciam-se pela tecnologia utilizada, pela habilidade de detectar diferenças entre indivíduos, custo, facilidade de uso, consistência e reprodutibilidade. Segundo Milach (1998), os tipos de marcadores moleculares dividem-se em dois grupos, conforme a técnica: hibridização (fundamentado em enzimas de restrição) ou amplificação de DNA (PCR).

Entre os marcadores mais conhecidos identificados por hibridização estão os marcadores RFLP e minissatélites ou locos VNTR (Variable Number of Tandem Repeats; JEFFREYS, WILSON \& THEIN, 1985). Na classe de marcadores revelados por amplificação, estão os marcadores RAPD (Random Amplified Polymorphic DNA; WILLIAMS et al., 1990), os microssatélites ou SSR (Simple Sequence Repeat; LITT \& LUTTY, 1989) e os ISSR (Inter Simple Sequence Repeat; ZIETKIEWICZ, RAFALSKI \& LABUDA, 1994). AFLP (Amplified Fragment Length Polymorphism; VOS et al., 1995), outra tecnologia utilizada para análise do polimorfismo molecular, é uma metodologia híbrida entre os dois procedimentos básicos, pois inclui uma etapa dirigida por enzimas de restrição, seguida pela síntese por PCR dos fragmentos de DNA obtidos pela digestão enzimática. Possivelmente, a maior utilidade prática destas metodologias foi o desenvolvimento de detalhado mapeamento cromossômico em uma variedade de organismos, o que contribuiu para o conhecimento atual dos genomas vegetais. O melhoramento genético clássico também usufruiu das vantagens do uso de marcadores moleculares e, atualmente, são bem estabelecidas estratégias de seleção indireta de marcadores genéticos ligados a características simples ou quantitativas (GUPTA et al., 1999).

Entre os tipos de marcadores moleculares derivados de PCR, encontram-se aqueles obtidos através de pri- 
mers não específicos. Sua popularidade provavelmente decorre da ausência de conhecimento a priori do genoma da espécie-alvo, tornando-os especialmente adequados àquelas situações em que não há pesquisa genética prévia, um fato bastante corriqueiro na maioria das espécies não domesticadas (NYBOM, 2004). Por exemplo, ISSR são marcadores de DNA do tipo fingerprinting, e o polimorfismo é observado a partir do tamanho de sequências (Figura 1 A-C) que entremeiam microssatélites (GUPTA et al., 1994; ZIETKIEWICZ, RAFALSKI \& LABUDA, 1994). São considerados como semi-arbitrários, multilocos, de ampla distribuição ao longo do genoma e de evolução rápida, amplificados através de PCR usando um único primer, desenhado a partir de uma repetição di- ou trinucleotídeo, a qual pode ser ancorada ou não (ZIETKIEWICZ, RAFALSKI \& LABUDA, 1994; GODWIN, AITKEN \& SMITH, 1997). Por suas características, podem ser utilizados para a caracterização molecular de cultivares e de níveis taxonômicos inferiores, em análise da diversidade, fingerprinting e mapeamento genômico.

Outra maneira de classificar os marcadores moleculares leva em consideração a possibilidade de identifi- cação de heterozigotos. Nesse tipo de classificação, os marcadores são denominados dominantes, quando os genótipos heterozigotos não são identificados (ou seja, obtém-se um padrão simples de presença ou ausência de bandas), ou codominantes, quando é possível identificar heterozigotos. Marcadores do tipo microssatélites são considerados marcadores codominantes, enquanto marcadores do tipo RAPD e ISSR são tratados como marcadores dominantes. Duas características fazem com que a análise estatística de marcadores dominantes seja menos informativa em comparação aos codominantes: a sua natureza bialélica e dominante. Normalmente, bandas ISSR são codificadas como presentes ou ausentes, resultando em uma matriz binária de caracteres. No caso da banda presente, há dificuldade em distinguir os indivíduos heterozigotos, a menos que o genótipo seja inferido através de estudos de pedigree (LYNCH; MILLIGAN, 1994; NYBOM, 2004; BONIN, EHRICH \& MANEL, 2007). Isso faz com que a análise estatística de marcadores dominantes torne-se sujeita a pressupostos adicionais (LYNCH \& MILLIGAN, 1994). O uso concomitante de metodologias tradicionais de estimativa de

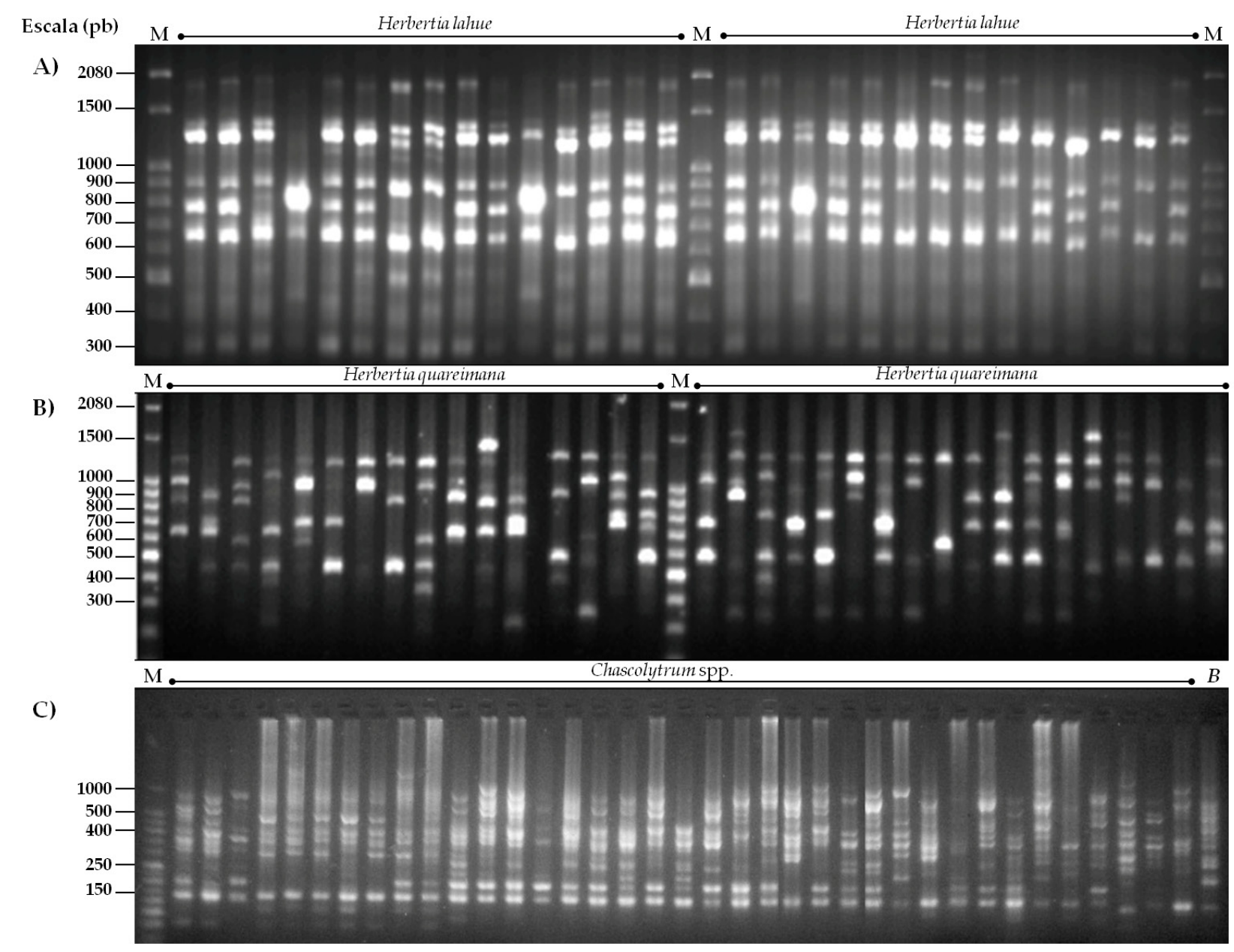

Figura 1. Perfil eletroforético obtido via PCR para marcadores ISSR, utilizando o primer SP03 em amostras de Herbertia lahue (A) e Herbertia quareimana (B), e o primer ISSR3 em amostras de Chascolytrum e Briza minor (C). $\mathrm{M}=$ marcador; $\mathrm{B}=$ Briza minor. 
frequência alélica e procedimentos probabilísticos (a análise Bayesiana) constitui uma prática interessante que visa consolidar os resultados (BONIN, EHRICH \& MANEL, 2007; GEORGE, SHARMA \& YADON, 2009).

No caso dos marcadores dominantes, as estimativas de frequência alélica exigem que pressupostos adicionais sejam adotados, ou que informações sobre o coeficiente de inbreeding das populações analisadas estejam disponíveis (BONIN, EHRICH \& MANEL, 2007). Os procedimentos que levam a estas estimativas enfatizam o nível de população. Muitas dessas estatísticas assumem o equilíbrio de Hardy-Weinberg em suas derivações, o que determina um viés na análise. Entretanto, o método Bayesiano de análise implementado por Holsinger, Lewis e Dey (2002) não considera o pressuposto de Hardy-Weinberg nos cálculos, bem como não assume um conhecimento a priori do grau de inbreeding dentro das populações em estudo. Desta maneira, esse tipo de estimativa surge como uma alternativa de análise para marcadores bialélicos e, de fato, tem sido bastante utilizada para inferir parâmetros de genética de populações em espécies vegetais (BONIN, EHRICH \& MANEL, 2007; GEORGE, SHARMA \& YADON, 2009).

A análise molecular da variância (AMOVA), desenvolvida por Excoffier, Smouse e Quattro (1992), caracteriza outra metodologia para estimativas de estruturação genética de populações. A base para essa análise, no caso de marcadores dominantes, é o cálculo de uma matriz de distâncias fenotípicas, cujos componentes são tratados como desvios da média de um grupo. Trata-se de uma estatística facilmente aplicável em diversas situações e amplamente utilizada para a análise de populações vegetais.

A análise molecular da diversidade dos táxons tem se mostrado útil no desenvolvimento de estratégias conservacionistas, bem como para a compreensão dos processos evolutivos envolvidos na diversificação. A obtenção de marcadores polimórficos é crucial para estimativas confiáveis de diversidade genética, visto que marcadores moleculares diversos mostram níveis diferentes de divergência genética, dependente principalmente da taxa evolutiva intrínseca a cada região genômica (WOLFF \& MORGAN-RICHARDS, 1998).

Em Iridaceae (Asparagales), uma melhor compreensão do relacionamento filogenético foi alcançada após utilizar regiões do genoma plastidial nas análises (SOUZACHIES et al., 1997; REEVES et al., 2001; GOLDBLATT et al., 2008). Atualmente, uma maior resolução filogenética para complexos de gêneros ou espécies de Iridaceae tem sido obtida combinando análises moleculares, citogenética, morfologia, biologia floral e biogeografia (GOLDBLATT, BERNHARDT \& MANNING, 2002; WILSON, 2003, 2004, 2011; RODRIGUEZ, SYTSMA, 2006; PETERSEN et al., 2008; CHAUVEAU et al., 2011, 2012; LOVO; WINKWORTH \& MELLO-SILVA, 2012; KARST \& WILSON, 2012).

Iridaceae (Figura 2 A-C) compreende cerca de 2.030 espécies distribuídas entre 65 a 75 gêneros (GOLDBLATT et al., 2008; APG III, 2009). Esta é uma família botânica de grande importância, não somente por apresentar várias espécies utilizadas em jardinagem, mas também pela ampla presença como componente de várias formações vegetais. O interesse econômico em Iridaceae é bastante difundido nos países da Europa e dos Estados Unidos, onde cultivos comerciais visando a indústria de flores de corte para paisagismo de jardins são importante fonte de renda (GOLDBLATT, MANNING \& RUDALL, 1998; GOLDBLATT \& MANNING, 2008). Uma característica importante para a família é a extensa variação morfológica vista em alguns grupos, o que torna os relacionamentos internos complexos. Assim, marcadores moleculares têm sido utilizados com sucesso tanto para a caracterização molecular de cultivares e de espécies (CAIOLA, CAPUTO \& ZANIER, 2004; DE MARCO et al., 2009; MORAGA et al., 2010; RANJAN et al., 2010; TACUATIÁ et al., 2012b), quanto para a obtenção de estimativas de parâmetros de genética de populações (HANNAN \& ORICK, 2000; WRÓBLEWSKA et al., 2003; DE MARCO et al., 2009; TACUATIÁ et al., 2012a), ou mesmo, para auxiliar na investigação de mecanismos envolvidos na especiação, correlacionando com informações ecológicas (RYMER et al., 2010). O mérito desses estudos foi esclarecer a complexidade evolutiva de alguns grupos de Iridaceae, evidenciando que a citogenética e a biologia da polinização foram fundamentais para a diversificação e para a adaptação de novidades evolutivas surgidas na família.

As nossas análises combinando dados de marcadores moleculares ISSR, sistema reprodutivo e citogenética, produziram um panorama evolutivo para espécies de Herbertia Sweet (Figura 2-A), um pequeno gênero sul-americano presente constantemente em áreas de campo aberto no sul do Brasil. Herbertia se encontra agrupado dentro do chamado clado A de Tigridieae (CHAUVEAU et al., 2012), e suas espécies compartilham inúmeras similaridades quanto à morfologia vegetativa. Em Herbertia, a delimitação de algumas espécies ainda é confusa e uma série de características conspícuas ou não, tornam a complexidade evidente: variações intraespecíficas da morfologia floral, diversos níveis de ploidia e combinações de recompensa floral (pólen e/ou óleos florais).

Assim como para outras Iridaceae, o sistema reprodutivo foi importante para a evolução de Herbertia e pode-se inferir uma transição a partir da autoincompatibilidade (um estado predominante em espécies basais de Iridaceae) em direção à total autocompatibilidade [que é visível em Herbertia lahue (Molina) Goldblatt, (Figura 2-A)]. Provavelmente, a variação morfológica identificada em H. lahue é o resultado de uma complexa interação entre ocorrência de citótipos, autogamia e adaptação a nichos ecológicos diferenciados, o que também reflete nos parâmetros de genética de populações inferidos para a espécie: a diversidade genética intrapopulacional é baixa e as populações são bastante diferenciadas (Stiehl-Alves et al., in prep.). Outras espécies de Herbertia que pos- 

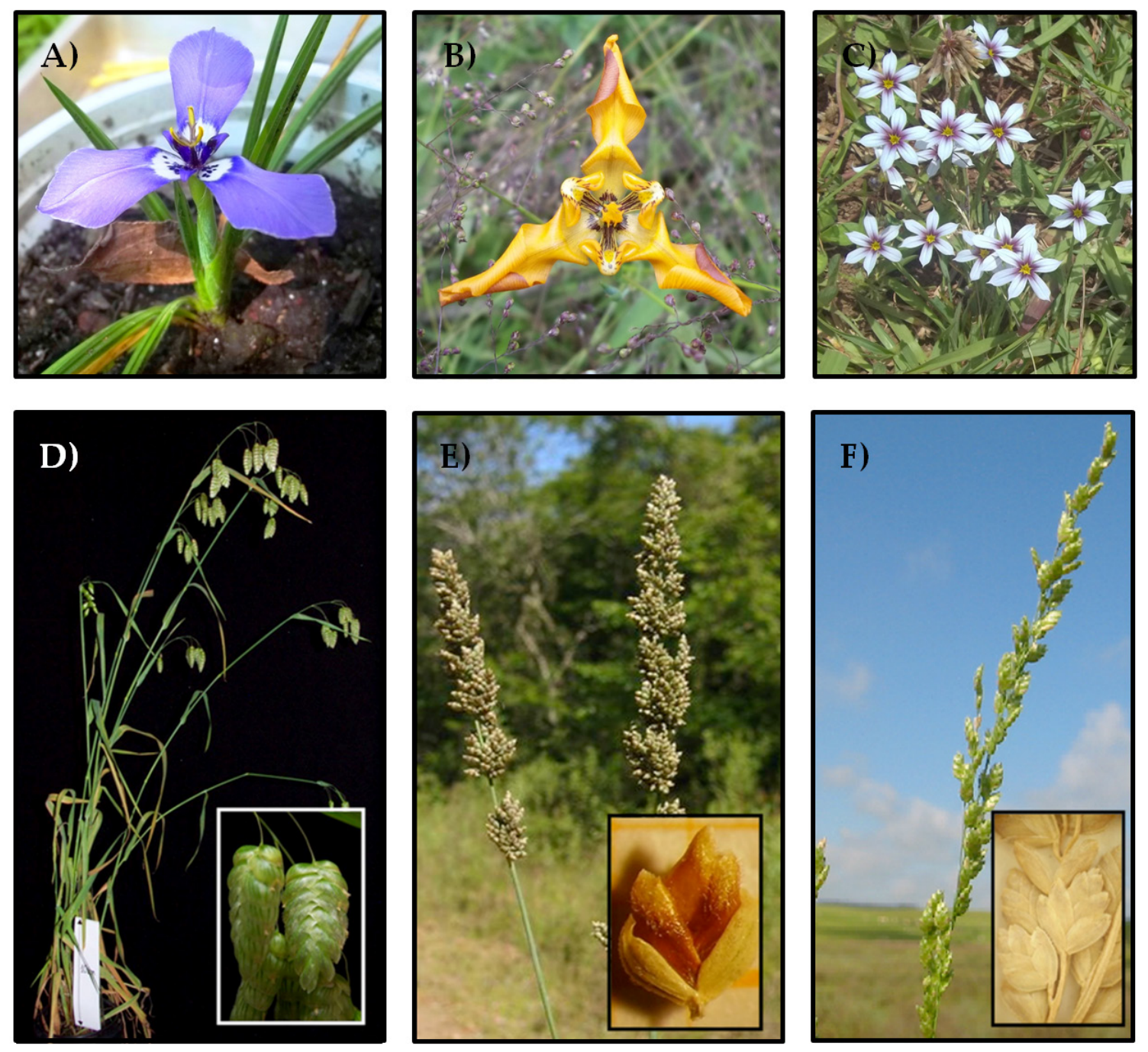

Figura 2. Espécies de Iridaceae e Poaceae encontradas em áreas de campo ao Sul do Brasil: Herbertia lahue (Molina) Goldblatt (A), Cypella fucata Ravenna (B), Sisyrinchium micranthum Cav. (C), Briza maxima L. (espécie exótica, adventícia) (D), Chascolytrum rufum J. Presl (E), e, Chascolytrum uniolae (Nees) L. Essi, Longhi-Wagner \& Souza-Chies (F).

suem algum tipo de barreira à autogamia, apresentaram estimativas de diversidade genética intrapopulacional altas, coerentes com o esperado para espécies autoincompatíveis (Stiehl-Alves et al., in prep.). De um modo geral, nós observamos que as populações são bastante diferenciadas geneticamente, algo já evidenciado em outros estudos em Iridaceae (HANNAN \& ORICK, 2000; WRÓBLEWSKA et al., 2003; DE MARCO et al., 2009; RYMER et al., 2010; TACUATIÁ et al., 2012a). Possivelmente, o sistema de dispersão de sementes tem forte impacto na diferenciação genética de populações de Iridaceae, visto que, caracteristicamente, a barocoria permite que as sementes sejam alocadas por distâncias restritas intra-populacionalmente.

Em Poaceae (Poales; Figura 2 D-F), os dados moleculares têm trazido contribuições valiosas para a compreensão de sua evolução e sistemática. Trata-se de uma família cosmopolita, que apresenta taxonomia complexa, por ser muito diversificada em termos taxonômicos, porém relativamente homogênea vegetativamente. A determinação e classificação dos táxons é bastante dependente de caracteres pouco conspícuos das estruturas reprodutivas ou mesmo de morfologia interna. São cerca de 10.000 espécies no mundo (CLAYTON \& RENVOIZE, 1986), sendo 1.429 com ocorrência confirmada no Brasil (FILGUEIRAS et al., 2014). Diversos grupos de gramíneas apresentam problemas de circunscrição, sendo os estudos evolutivos muitas vezes dificultados devido à ocorrência frequente de híbridos naturais, poliploidia e apomixia.

Estudos com marcadores dominantes e co-dominantes baseados em PCR têm sido utilizados há muito tempo na elucidação da variabilidade genética de espécies exóticas cultivadas e nativas, bem como em programas 
de melhoramento vegetal. No caso de Poaceae, o uso de dados de sequências de DNA nucleares e plastidiais têm colaborado para a compreensão dos relacionamentos filogenéticos em diversas categorias taxonômicas, desde a proposição de novos arranjos no nível de subfamília (GPWG, 2001; GPWG II, 2012), tribos (SÁNCHEZ-KEN \& CLARK, 2010) subtribos (MATHEWS et al., 2002), até gêneros e espécies (BARKER et al., 2003; CHEMISQY et al., 2010; ESSI, LONGHI-WAGNER \& SOUZA-CHIES, 2008). Embora Poaceae venha sendo investigada com o uso de ferramentas da biologia molecular há muitos anos, por se tratar de uma família com grande importância econômica, a compreensão plena de sua evolução está longe de ser atingida.

Uma das principais aplicações dos marcadores moleculares para a família tem sido na elucidação de controvérsias taxonômicas. Alguns táxons de gramíneas vêm sendo abordados por nosso grupo de pesquisa, em parceria com pesquisadores de diversas instituições do Brasil. Estudos do gênero Paspalum L. (FERREIRA, SOUZA-CHIES, 2005; SOUZA-CHIES et al., 2006; ESSI \& SOUZA-CHIES, 2007) demonstraram que certos grupos informais amplamente aceitos pelos especialistas não compunham grupos naturais, sendo necessárias reconsiderações taxonômicas. Também foi investigado um complexo de espécies e gêneros afins de gramíneas microtérmicas - o Complexo Briza (ESSI, LONGHI-WAGNER \& SOUZA-CHIES, 2008; Figura 2 D-F), e graças aos resultados de análises filogenéticas utilizando sequências de DNA, elucidou-se parte de sua problemática taxonômica e evolutiva, propondo-se um rearranjo dos gêneros envolvidos.

Além dos estudos que integram taxonomia clássica e filogenia, o grupo tem utilizado marcadores moleculares do tipo ISSR e microssatélites para avaliar a variabilidade genética de espécies de potencial forrageiro, como Paspalum notatum Alain ex Flüggé (CIDADE et al., 2008; CIDADE et al., 2009; CIDADE et al., 2010; CIDADE et al., 2013) e Paspalum atratum Swallen (CIDADE et al., 2013). Marcadores ISSR (Figura 1-C) também foram utilizados como complemento a dados morfológicos em decisões taxonômicas em estudo sobre o Complexo Briza (ESSI, 2007).

\section{Citogenética Vegetal}

A citogenética, ciência que estuda os cromossomos, sua arquitetura e comportamento, desenvolveu-se principalmente a partir do início do século passado e seu crescente progresso acompanhou o aprimoramento de técnicas e equipamentos de microscopia. Desde então, grandes avanços metodológicos e conceituais tem se acumulado levando à caracterização de genomas de diferentes espécies, e, assim, contribuindo para o conhecimento básico e aplicado em diversas áreas, como o melhoramento genético, a genética médica, a mutagênese, e, sobretudo, na taxonomia e evolução.

Desde o início do século XX a taxonomia tem feito uso de dados citogenéticos (GUERRA, 1990). Estudos citotaxonômicos são, em sua grande maioria, voltados a grupos taxonômicos de regiões temperadas, em especial, à flora europeia e à norte-americana. Entretanto, os mecanimos evolutivos cariológicos podem não ser os mesmos em plantas temperadas e tropicais, portanto não possuindo o mesmo significado. Por esse motivo e baseado em evidências (STEBBINS, 1966; LEVIN \& FUNDERBURG, 1979) que comprovaram esta hipótese, Guerra (1990) aponta para a necessidade de desenvolvimento de muitos mais estudos citogenéticos em plantas tropicais que busquem significados evolutivos e taxonômicos para tal discrepância.

O uso da citotaxonomia contribui para a avaliação das relações genéticas entre espécies ou populações e para um melhor entendimento de como elas divergiram entre si, uma vez que o cariótipo se mantém razoavelmente estável mesmo diante de variações ambientais ou àquelas que ocorrem ao longo do desenvolvimento do indivíduo (GUERRA, 1988, 2008). Alguns aspectos do cariótipo são claros indicadores de aberrações na meiose ou esterilidade, barreiras reprodutivas ou processo evolutivo unidirecional. Ainda que seja considerado o parâmetro mais simples do cariótipo, a determinação do número cromossômico apresenta algumas vantagens para a citotaxonomia, sendo a técnica mais rápida, barata e fácil de obter informações importantes a respeito do genoma de uma espécie. Além disso, o número cromossômico é o dado taxonômico mais conhecido para todas as famílias e para a maioria dos gêneros de plantas (GUERRA, 2008). A partir da determinação do número cromossômico de um conjunto de espécies de um dado táxon é possível traçar a evolução cariotípica, inferindo o número básico ancestral do grupo, as possíveis linhas evolutivas ocorridas e ainda correlacionar essas linhas com os grupos taxonômicos estabelecidos (ALVES, 2013).

Outras informações citogenéticas relevantes também podem ser agregadas ao número cromossômico, tais como tamanho e morfologia cromossômicos, simetria cariotípica, padrão de bandas, e número e posição de satélites cromossômicos (GUERRA, 2008). A citogenética convencional mediante análises como contagem cromossômica, análise da arquitetura cariotípica, observação do comportamento meiótico e avaliação polínica, têm possibilitado ampliar a visão sobre a diferenciação de inúmeras espécies.

Existem alguns fatores que podem dificultar a determinação de números cromossômicos e seu uso para a citotaxonomia em algumas espécies, como a necessidade de material vegetal vivo e com tecidos em crescimento ativo, bem como o fato de que muitos gêneros apresentam baixa variabilidade quanto ao seu número cromossômico. Porém, apesar dessa pouca variabilidade, em muitos taxa o número cromossômico é um marco importante para a distinção de grupos monofiléticos (GUERRA, 2008). 
No que se pode chamar de citotaxonomia moderna, métodos mais refinados vem sendo empregados nas análises de cromossomos, aliando técnicas clássicas a outras mais avançadas. Nesse caso, a caracterização do cariótipo é complementada pela determinação da quantidade de DNA, técnicas de bandeamento e de hibridização in situ, as quais resultam numa diferenciação cromossômica longitudinal. Tais métodos são algumas vezes mais laboriosos e dispendiosos do que os métodos convencionais de análise, contudo, podem oferecer um volume de informações imenso permitindo uma melhor caracterização da variabilidade cariológica e genômica (GUERRA, 1990). Tais análises são especialmente úteis em grupos mais problemáticos taxonomicamente.

Apesar de sua simplicidade frente a técnicas mais arrojadas e de suas ocasionais desvantagens, o número cromossômico ainda é o parâmetro mais amplamente utilizado e do qual se dispõe de maior volume de dados (RAVEN, 1975). Além disso, por meio da simples contagem cromossômica, é possível diagnosticar facilmente um dos fenômenos citogenéticos mais comuns e importantes na evolução vegetal - a poliploidia. Alterações no número cromossômico podem ocorrer por diferentes vias, porém duas delas têm se mostrado de grande relevância na evolução de inúmeras famílias: a poliploidia (duplicação ou multiplicação de um complemento cromossômico inteiro) e a disploidia (aumento ou redução do número cromossômico em virtude de eventos de fusão e fissão) (GUERRA, 2008). Dentre estes mecanismos de mudança no número cromossômico, o que recebe maior atenção é a poliploidia, visto que genomas de diversos eucariotos apresentam evidências de eventos passados de duplicação (MAYROSE, BARKER \& OTTO, 2010). Porém, é em plantas que se observa este fenômeno mais marcadamente e acredita-se que $50-100 \%$ das angiospermas tenham ancestralidade poliploide (GOLDBLATT, 1980; MASTERSON, 1994; CUI et al., 2006; SOLTIS et al ,2009). A maioria das espécies de angiospermas descendeu de ancestrais que tiveram seus genomas duplicados por autopoliploidia ou alopoliloidia (VAN DE PEER, MAERE \& MEYER, 2009). A poliploidia teve um papel importante na evolução das angiospermas, mas sua frequência é muito variável entre as famílias de plantas superiores (LEITCH \& BENNETT, 1997). Tamanha é a importância da poliploidia na evolução das plantas, que há estimativas de que 15\% dos eventos de especiação em angiospermas e $31 \%$ em pteridófitas foram acompanhados pelo aumento do nível de ploidia (WOOD et al., 2009).

Particularmente, a alopoliploidia representa um aspecto importante na evolução e especiação das angiospermas. Nas angiospermas, a proporção da poliploidia pode superar $70 \%$, sendo que a maioria (75\%) é de alopoliploides (BROCHMANN et al., 2004). Nestes, o poliploide surge a partir da combinação de dois genomas diferentes oriundos de duas ou mais espécies ou gêneros ancestrais (LEITCH \& BENNETT, 1997). Os poliploides podem diferir significativamente de seus progenitores quanto à morfologia, fisiologia e histórias de vida (RAMSEY \& SCHEMSKE, 2002), levando ao estabelecimento e sucesso de uma espécie poliploide em novas configurações ecológicas (MAYROSE, BARKER \& OTTO, 2010). Mudanças estruturais no genoma, como é o caso da poliploidia, têm efeitos imediatos sobre o fenótipo e o fitness de um indivíduo e, portanto, podem servir como um importante mecanismo de diversificação ecológica, especialmente em condições ambientais extremas (OTTO, 2007).

Apesar da notória ocorrência de sucessivos episódios de duplicação genômica em plantas, a existência de poliploides modernos com genomas compactos e de comportamento dissômico como em Arabidopsis (DC.) Heynh., instigou a busca por compreensão dos mecanismos envolvidos no estabelecimento de poliploides. Hoje em dia se sabe que a poliploidia é seguida de uma reestruturação do genoma, na qual alguma parcela, mas não o todo, do material genômico redundante é eliminado (ADAMS \& WENDEL, 2005). Primeiramente consideravase que modificações nos genomas diploides parentais, uma vez dentro de um núcleo poliploide em comum, tivessem uma baixa representatividade; entretanto, sabe-se que esta reorganização pode se dar de maneira ampla e rápida (SOLTIS \& SOLTIS, 1999). Evidências de tais rearranjos são obtidas através da pintura cromossômica, mapeamento gênico e genética comparativa e mostram que estas podem ocorrer tanto dentro quanto entre os genomas parentais em um poliploide (SOLTIS \& SOLTIS, 1999). As implicações genéticas e evolutivas da poliploidização recorrente e reorganização do genoma são evidentes e ambos os processos representam fontes importantes de variabilidade genética (SOLTIS \& SOLTIS, 1999).

A poliploidia não é apenas acompanhada da reestruturação do genoma; também estão envolvidas alterações a nível gênico, como evolução em concerto e silenciamento gênico (SOLTIS \& SOLTIS, 1995; LEITCH \& BENNETT, 1997). Ao mecanismo de silenciamento gênico refere-se como 'diploidização' e em alguns casos de poliploidia ele pode ser tão extenso que o genoma deixa de estar estruturado como um alopoliploide. Portanto, quanto mais extenso for o processo de diploidização, mais difícil será discerni-lo (SOLTIS \& SOLTIS, 1999).

Os elementos transponíveis parecem, também, ter um papel facilitador na rápida reestruturação genômica após a poliploidização. Estes são componentes ubíquos e dinâmicos dos genomas eucarióticos e podem representar até $80 \%$ dos grandes genomas de cereais (BENNETZEN, 1996). Estes elementos tendem a se multiplicar e se manter em poliploides, pois as cópias adicionais mantidas por estes podem compensar a perda ou alteração da expressão de genes ocasionada, eventualmente, pela inserção do elemento de transposição (SOLTIS \& SOLTIS, 1999). Desse modo, a poliploidia permite uma extensa modificação de genes pelos elementos transponíveis (MATZKE \& MATZKE, 1998). 
Além de sua participação nos processos que sucedem a poliploidização, os elementos transponíveis são considerados uma das mais importantes fontes internas de variabilidade intraespecífica (BELYAYEV et al., 2010). Neste trabalho, que examina a evolução cromossômica do trigo selvagem diploide, os autores criam a hipótese de que a dinâmica dos elementos transponíveis poderia promover ou intensificar mudanças morfológicas e cariotípicas, fazendo com que espécies cujos genomas apresentam maior plasticidade sobrevivam como formas ou espécies diferentes em tempos de rápidas mudanças climáticas.

Com relação ao impacto da poliploidia na evolução vegetal, Poaceae é considerada uma das famílias-modelo no estudo da poliploidia em angiospermas. Aceita-se que a maioria das espécies da família, se não todas, sejam poliploides. Pode-se encontrar na família todos os principais tipos de poliploides: autopoliploides, alopoliploides e alopoliploides segmentares (LEVY \& FELDMAN, 2002). Gramíneas cultivadas, tais como trigo, o milho e o arroz possuem sistemas genéticos bem estudados, cada um correspondendo a um protótipo poliploide (LEVY \& FELDMAN, 2002). Destes, o trigo representa um dos exemplos melhor caracterizados de evolução através de alopoliploidia.

Muitos estudos em citogenética têm auxiliado na compreensão da evolução das espécies brasileiras de gramíneas. Espécies do gênero Paspalum vêm sendo investigadas há décadas, sendo que a partir da década de 1980 foram intensificados estudos quanto ao número de cromossomos (POZZOBON \& VALLS, 1997; TAKAYAMA et al., 1998; POZZOBON, VALLS \& SANTOS, 2000; PAGLIARINI et al., 2001), relações citogenéticas (QUARIN \& BURSON, 1983), citogeografia (POZZOBON \& VALLS, 2000), e as informações obtidas em tais estudos têm sido utilizadas na compreensão do modo de reprodução e evolução do gênero. Estudos filogenéticos do nosso grupo de pesquisa foram bastante beneficiados com tal conhecimento acumulado em citogenética de espécies de Paspalum.

Na família Iridaceae, a poliploidia também é considerada um mecanismo importante na evolução de suas espécies (ALVES et al, 2011). Um bom exemplo disso é Sisyrinchium L., em que a poliploidia já foi observada em mais de 70\% das espécies estudadas (GOLDBLATT \& TAKEI, 1997). Das 14 espécies de Sisyrinchium cujos números cromossômicos foram obtidos pelo nosso grupo de pesquisa, Sisyrinchium micranthum Cav. (Figura 2-C) é um exemplo onde foram observados citótipos intraespecíficos, contemplando três diferentes níveis de ploidia (TACUATIÁ et al., 2012b). Também para Herbertia já foi encontrado mais de um nível de ploidia $(2 x, 4 x$, 6x e 8x) (WINGE, 1959; GOLDBLATT \& TAKEI, 1997; ROITMAN \& CASTILLO, 2004; MORENO et al., 2009). Confirmando estes estudos, nosso grupo observou os mesmos níveis de ploidia dentre as seis espécies estudadas de Herbertia endêmicas da região Sul do Brasil
(SOUZA-CHIES et al., 2012).

Uma importante ferramenta que pode ser empregada para inferir o nível de ploidia é a estimativa do tamanho do genoma. O conhecimento da quantidade de DNA nuclear, ou valor $\mathrm{C}$, tem fundamental valor biológico e pode ser útil em vários campos da ciência como biologia molecular e celular, ecologia, fitogeografia e sistemática (BENNET \& LEITCH, 1995). A estimativa do tamanho do genoma pode substituir a contagem de cromossomos, sendo especialmente útil quando se trabalha com um grande número de indivíduos (SCHIFINO-WITTMANN, 2001).

Assim como o número cromossômico, o conteúdo de DNA varia muito em angiospermas, mesmo entre espécies proximamente relacionadas, podendo apresentar uma variação de mais de 2000 vezes no tamanho do genoma (GAUT \& ROSS-IBARRA, 2008). Essa variação é produzida, em última instância, por mecanismos mutacionais, que incluem segregação desigual de cromossomos (BENNETT \& SMITH, 1976), erros na replicação de DNA (BEBENEK \& KUNKEL, 1990), poliploidização (SOLTIS \& SOLTIS, 1999), duplicação gênica (CUI et al., 2006) e a proliferação de elementos transponíveis (DEVOS, BROWN \& BENNETZEN, 2002).

Soltis et al. (2003) observaram que o tamanho genômico ancestral das angiospermas é muito pequeno (1C $\leq 1,4$ pg), em concordância com análises anteriores de Leitch, Chase e Bennett (1998). Ademais, este reduzido conteúdo de DNA é ancestral não somente nas angiospermas em geral, mas também nos mais importantes clados de plantas com flores, incluindo as monocotiledôneas e as eudicotiledôneas (SOLTIS et al., 2003). Em Iridaceae, a evolução cariotípica tem sido acompanhada por aumentos e reduções no tamanho de genoma (GOLDBLATT, WALBOT \& ZIMMER, 1984). Em espécies de Sisyrinchium, cujas estimativas foram as primeiras realizadas, o conteúdo genômico haploide (valor C) varia de 0,25 a 3,26 pg (GOLDBLATT, WALBOT \& ZIMMER, 1984; KENTON, RUDALL \& JOHNSON, 1986; KENTON et al., 1990). Nas espécies de Sisyrinchium do sul do Brasil estudadas por nosso grupo, observou-se uma pequena variação no tamanho genômico monoploide $(C x)$, podendo esta redução ser justificada pelo fenômeno de downsizing (SOUZA-CHIES et al., 2012). De acordo com os resultados obtidos pelo grupo, Calydorea Herb., Cypella Herb. (Figura 2-B) e Herbertia apresentam tamanhos de genoma consideravelmente maiores (SOUZA-CHIES et al., 2012). O estudo do conteúdo de DNA nuclear continua merecendo interesse principalmente pelas marcantes diferenças no tamanho genômico existente a nível infragenérico, podendo ser usado para demarcar vários taxa (OHRI, 1998).

Poaceae é a família vegetal com o maior volume de dados relativos a tamanho de genoma, chegando a 807 espécies já determinadas. O valor 1C médio é de 5,52 pg, com quantidades que variam enormemente entre $0,30 \mathrm{e}$ 26,00 pg (LEITCH et al., 2010). Tal variação é esperada, 
uma vez que o número cromossômico na família varia de $2 \mathrm{n}=4$ a 266. Considerando que a base de dados disponível para Poaceae, tanto para quantidade de DNA, quanto para número cromossômico é bastante grande, inúmeros estudos vem sendo feitos quanto à evolução do genoma nas gramíneas. Tem sido verificada uma modificação rápida e dinâmica no tamanho do genoma, com uma importante contribuição de transposons e retrotransposons (LEITCH et al., 2010). Especificamente para o gênero Paspalum, existem determinações de tamanho de genoma para 13 espécies, com um valor 1C médio de 1,19 pg, variando de 0,62 a 1,79 pg (Plant DNA C-values Database, BENNETT \& LEITCH, 2012).

\section{Considerações finais}

Quando surgiram as primeiras propostas de uso de marcadores moleculares para o estudo da evolução vegetal, houve diversas especulações quanto à possibilidade de que um dia tais estudos substituíssem por completo os estudos em citogenética clássica e até mesmo estudos morfológicos. Ao mesmo tempo em que os primeiros resultados traziam excitação a alguns grupos de pesquisa, traziam desconfiança a outros grupos, resultando em debates acalorados no meio científico, especialmente no momento em que tais dados passaram a ser utilizados para justificar proposições taxonômicas. Entretanto, o caos preconizado por alguns pesquisadores nunca se concretizou, e, na medida em que o conhecimento sobre genética e biologia molecular foi democratizado e desmistificado, os estudos passaram a ser cada vez mais integradores. Hoje se percebe uma rotina de estudos integrando morfologia, citogenética, marcadores moleculares, filogenia, e uma maior naturalidade na avaliação de trabalhos com propostas de metodologias mistas. Curiosamente, a própria taxonomia clássica foi revigorada, quando muitas situações taxonômicas de grupos aparentemente estáveis precisaram ser revistas à luz dos resultados de estudos moleculares. O exemplo mais notório dessa situação é a mudança proposta para a classificação das angiospermas, pelo grupo de filogenia das angiospermas (APG I, 1998; APG II, 2003; APG III, 2009), que requereu uma reavaliação de caracteres de morfologia externa e interna, resgatando a importância da morfologia polínica, por exemplo.

Nesse ambiente efervescente, os estudos conduzidos por nosso grupo de pesquisa para Iridaceae e Poaceae têm acompanhado as tendências mundiais de estudos integrados, contribuindo não apenas para o esclarecimento de cenários evolutivos mais amplos, como também preparando mão-de-obra especializada e familiarizada com trabalhos em equipes multidisciplinares. Atualmente, o nosso grupo tem acumulado indícios voltados à evolução de gêneros taxonomicamente complexos, buscando futuramente correlacionar essas informações de forma lógica, a fim de oferecer um panorama evolutivo coe- rente com o processo de diversificação visto em grupos sul-americanos de Iridaceae e de Poaceae. Os exemplos mais contundentes de complexidade taxonômica com os quais nos defrontamos são encontrados em Sisyrinchium e Cypella (Iridaceae), Paspalum e Chascolytrum (Poaceae) e as informações obtidas até o momento pela nossa equipe já conseguem explicar o panorama filogenético atualmente proposto para estes grupos.

\section{Referências}

ADAMS, K. L.; WENDEL, J. F. Polyploidy and genome evolution in plants. Current Opinion in Plant Biology, v. 8, n. 6, p. 135-141. 2005.

ALVES, L. I. F. Evolução cariotípica da tribo Trimezieae (Iridoideae-Iridaceae) com ênfase nos gêneros Neomarica Sprague e Trimezia Salisb. ex Herb. Tese de Doutorado - Universidade Federal da Paraíba, Areia: UFPB. 2013. 94 p.

\section{ALVES, L. I. F.; LIMA, S. A. A.; FELIX, L. P.} Chromosome characterization and variability in some Iridaceae from Northeastern Brazil. Genetics and Molecular Biology, v. 34, n. 2, p. 259-267. 2011.

APG I (The Angiosperm Phylogeny Group). An ordinal classification for the families of flowering plants. Annals of the Missouri Botanical Garden, v. 85, n. 4, p. 531-553. 1998.

APG II (The Angiosperm Phylogeny Group). An update of the Angiosperm Phylogeny Group classification for the orders and families of flowering plants: APG II. Botanical Journal of the Linnean Society, v. 141, n. 4, p. 399-436. 2003.

APG III (The Angiosperm Phylogeny Group). An update of the Angiosperm Phylogeny Group classification for the orders and families of flowering plants: APG III. Botanical Journal of the Linnean Society, v. 161, n. 2, p. 105-121. 2009.

ARIAS, M. C.; INFANTE-MALACHIAS, M. E. RFLP: O emprego de enzimas de restrição para a detecção de polimorfismos no DNA. In: MATIOLI, R. S. (ed.) Biologia Molecular e Evolução. Ribeirão Preto: Holos, 2001. p. 143-152.

AVISE, J.C. Molecular Markers, Natural History, and Evolution. New York: Chapman \& Hall, 1994. 511 p.

BARKER, N. P.; LINDER, H. P.; MORTON, C. M.; LYLE, M. The paraphyly of Cortaderia (Danthonioideae; Poaceae): evidence from 
morphology and chloroplast and nuclear sequence data. Annals of the Missouri Botanical Garden, v. 90, n. 1, p. 1-24. 2003.

BEBENEK, K.; KUNKEL, T. A. Frameshift errors initiated by nucleotide misincorporation. Proceedings of the National Academy of Sciences of the United States of America, v. 87, n. 13, p. 4946-4950. 1990.

BELYAYEV, A.; KALENDAR, R.; BRODSKY, L.; NEVO, E.; SCHULMAN, A. H.; RASKINA, O. Transposable elements in a marginal plant population: temporal fluctuations provide new insights into genome evolution of wild diploid wheat. Mobile DNA, v. 1, n. 6, p. 1-16. 2010.

BENNET, M. D.; LEITCH, I. J. Nuclear DNA amounts in angiosperms: progress, problems and prospects. Annals of Botany, v. 76, n. 2, p. 113-176, 1995.

BENNETT, M. D.; LEITCH, I. J. Plant DNA C-values Database. 2012. Kew Royal Botanic Gardens. Disponível em: <http://www.kew.org/cvalues/>. Acesso em: 20 jan. 2014.

BENNETT, M. D.; SMITH, J. B. Nuclear DNA amounts in angiosperms. Philosophical Transactions of the Royal Society B: Biological Sciences, v. 274, p. 227-274. 1976.

BENNETZEN, J. L. The contributions of retroelements to plant genome organization, function and evolution. Trends in Microbiology, v. 4, p. 347-353. 1996.

BONIN, A.; EHRICH, D.; MANEL, S. Statistical analysis of amplified fragment length polymorphism data: a toolbox for molecular ecologists and evolutionists. Molecular Ecology, v. 16, n. 18, p. 3737-3758. 2007.

BROCHMANN, C.; BRYSTING, A. K.; ALSOS, I. G.; BORGEN, L.; GRUNDT, H. H.; SCHEEN, A. C.; ELVEN, R. Polyploidy in arctic plants. Biological Journal of the Linnean Society, v. 82, n. 4, p. 521536. 2004.

CAIOLA, M. G.; CAPUTO, P.; ZANIER R. RAPD Analysis in Crocus sativus L. accessions and related Crocus species. Biologia Plantarum, v. 48, n. 3, p. 375-380. 2004.

CHAUVEAU, O.; EGGERS, L.; RAQUIN, C.; SILVÉRIO, A.; BROWN, S.; COULOUX, A.; CRUAUD, C.; KALTCHUK-SANTOS, E.; YOCKTENG, R.; SOUZA-CHIES, T. T.; NADOT,
S. Evolution of oil-producing trichomes in Sisyrinchium (Iridaceae): insights from the first comprehensive phylogenetic analysis of the genus. Annals of Botany, v. 107, p. 1287-1312. 2011.

CHAUVEAU, O.; EGGERS, L.; SOUZA-CHIES, T. T.; NADOT, S. Oil-producing flowers within the Iridoideae (Iridaceae): evolutionary trends in the flowers of the New World genera. Annals of Botany, v. 110, p. 1-17. 2012.

CHEMISQY, M. A.; GIUSSANI, L. M.; SCATAGLINI, M. A.; KELLOGG, E. A.; MORRONE, O.

Phylogenetic studies favour the unification of Pennisetum, Cenchrus and Odontelytrum (Poaceae): a combined nuclear, plastid and morphological analysis, and nomenclatural combinations in Cenchrus. Annals of Botany, v. 106, p. 107-130. 2010.

CIDADE, F. W.; DALL'AGNOL, M.; BERED, F.; SOUZA-CHIES, T. T. Genetic Diversity of the complex Paspalum notatum Flügge (Paniceae: Panicoideae). Genetic Resources and Crop Evolution, v. 55, p. 235-246. 2008.

CIDADE, F. W.; SOUZA-CHIES, T. T.; BATISTA, L. A. R.; DALL'AGNOL, M.; ZUCCHI, M. I.; JUNGMANN, L.; SOUZA, A. P. Isolation and characterization of microsatellite loci in Paspalum notatum Flüggé (Poaceae). Conservation Genetics, v. 10, p. 1977-1980. 2009. Disponível em: <http:// link.springer.com/article/10.1007\%2Fs10592-0099872-6\#page-1>. Acesso em: 23 jan. 2014.

CIDADE, F. W.; SOUZA-CHIES, T. T.; SOUZA, F. H. D.; BATISTA, L. A. R.; DALL'AGNOL, M.; VALLS, J. F. M.; ZUCCHI, M. I.; SOUZA, A. P. Microssatellite loci for Paspalum atratum (Poaceae) and cross-amplification in other species. American Journal of Botany. e107-e110. 2010. Disponível em: <http://www.amjbot.org/content/97/11/e107.full. pdf+html>. Acesso em: 23 jan. 2014.

CIDADE, F. W.; VIGNA, B. B. Z.; SOUZA, F. H. D.; VALLS, J. F. M.; DALL'AGNOL, M.; ZUCCHI, M. I.; SOUZA-CHIES, T. T.; SOUZA, A. P. Genetic variation in polyploid forage Grass: assessing the molecular genetic variability in the Paspalum genus. BMC Genetics, v. 14, n. 50, p. 1-18. 2013. Disponível em: <http://link.springer.com/ article/10.1186\%2F1471-2156-14-50\#page-1>. Acesso em: 23 jan. 2014.

CLAYTON, W.D.; RENVOIZE, S.A. Genera Graminum: Grasses of the world. Kew Bulletin Additional Series XIII. Londres: Her Majesty's Stationery Office, 1986. 
CUI, L.; WALL, P. K.; LEEBEN-MACK, J-H.; LINDSAY, B. G.; SOLTIS, D. E., DOYLE, J. J.; SOLTIS, P. S.; CARLSON, J. E.; ARUMUGANATHAN, K.; BARAKAT, A.; ALBERT, V. A.; MA, H.; DE PAMPHILIS, C. W. Widespread genome duplications throughout the history of flowering plants. Genome Research, v. 16, n. 6, p. 738-749. 2006.

DE MARCO, E. G.; TACUATIÁ, L. O.; EGGERS, L.; KALTCHUK-SANTOS, E.; SOUZA-CHIES, T. T. Genetic variability within Cypella fucata Ravenna in southern Brazil. In: MAHONEY, C. L.; SPRINGER, D. A. (eds) Genetic Diversity. Nova Iorque: Nova Publishers, 2009. p. 179-194.

DEVOS, K. M.; BROWN, J. K. M.; BENNETZEN, J. L. Genome size reduction through illegitimate recombination counteracts genome expansion in Arabidopsis. Genome Research, v. 12, n. 7, p. 10751079. 2002.

ESSI, L. Análise Filogenética e Taxonômica do Complexo Briza (Poaceae: Poeae). 2007. Tese de Doutorado - Universidade Federal do Rio Grande do Sul, Porto Alegre: UFRGS. 2007. 277 p.

ESSI, L.; LONGHI-WAGNER, H. M.; SOUZA-CHIES, T. T. Phylogenetic analysis of the Briza Complex (Poaceae). Molecular Phylogenetics and Evolution, v. 47, n. 3, p. 1018-1029. 2008.

ESSI, L.; SOUZA-CHIES, T. T. Phylogeny of Linearia and Notata groups of Paspalum L. (Poaceae, Panicoideae, Paniceae) and related species. Genetic Resources and Crop Evolution, v. 54, p. 779-791. 2007.

EXCOFFIER, L.; SMOUSE, P.E.; QUATTRO, J.M. Analysis of molecular variance inferred from metric distances among DNA haplotypes: application to human mitochondrial DNA restriction data. Genetics, v. 131, p. 479-491. 1992.

FERREIRA, T. F.; SOUZA-CHIES, T. T. Genetic diversity among Paspalum L. species (Poaceae) belonging to the Notata and Linearia groups based on restriction fragment length polymorphism analyses. Genetica, v. 125, p. 133-140. 2005.

FILGUEIRAS, T. S.; LONGHI-WAGNER, H. M.; VIANA, P. L.; ZANIN, A.; OLIVEIRA, R. C. DE; CANTO-DOROW, T. S.; SHIRASUNA, R. T.; VALLS, J. F. M.; OLIVEIRA, R. P.; RODRIGUES, R. S.; SANTOS-GONÇALVES, A. P.; WELKER, C. A. D.; FERREIRA, F. M. Poaceae. In: Lista de Espécies da Flora do Brasil. Jardim Botânico do Rio de Janeiro. Disponível em: <http://floradobrasil.jbrj. gov.br/jabot/floradobrasil/FB193>. Acesso em: 21 jan. 2014.

GAUT, B. S.; ROSS-IBARRA, J. Selection on major components of angiosperm genomes. Science, $\mathrm{v}$. 320, p. 484-486. 2008.

GEORGE, S.; SHARMA, J.; YADON, V. L. Genetic diversity of the endangered and narrow endemic Piperia yadonii (Orchidaceae) assessed with ISSR polymorphisms. American Journal of Botany, v. 96, p. 2022-2030. 2009.

GODWIN, I. D.; AITKEN, E. A. B.; SMITH, L. W. Application of inter simple sequence repeat (ISSR) markers to plant genetics. Electrophoresis, v. 18, p. 1524-1528. 1997.

GOLDBLATT, P. Polyploidy in angiosperms: monocotyledons. In: LEWIS, W. H. (ed.). Polyploidy, v. 13. p. 219-239, 1980.

GOLDBLATT, P.; BERNAHRDT, P.; MANNING, J. C. Floral biology of Romulea (Iridaceae: Crocoideae): a progression from a generalist to a specialist pollination system. Adansonia, v. 24, n. 2, p. 243-262. 2002.

GOLDBLATT, P.; MANNING, J. C. The Iris Family: natural history and classification. Portland: Timber Press, 2008. 290 p.

GOLDBLATT, P.; MANNING, J. C.; RUDALL, P. Iridaceae. In: KUBITSKI, K. (ed.). The Families and Genera of Vascular Plants. Alemanha: Springer, p. 295-314. 1998.

GOLDBLATT, P.; RODRIGUEZ, A.; POWELL, M. P.; DAVIES, T. J.; MANNING, J. C.; VAN DER BANK, M.; SAVOLAINEN, V. Iridaceae 'Out of Australasia'? Phylogeny, biogeography, and divergence time based on plastid DNA sequences. Systematic Botany, v. 33, n. 3, p. 495-508. 2008.

GOLDBLATT, P.; TAKEI, M. Chromosome cytology of Iridaceae - patterns of variation, determination of ancestral base numbers, and modes of karyotype change. Annals of the Missouri Botanical Garden, v. 84, p. 285-304. 1997.

GOLDBLATT, P.; WALBOT, W.; ZIMMER, E. A. Estimation of genome size (C-value) in Iridaceae by cytophotometry. Annals of the Missouri Botanical Garden, v. 71, p. 176-180. 1984.

GRASS PHYLOGENY WORKING GROUP (GPWG). 
Phylogeny and subfamilial classification of the grasses (Poaceae). Annals of the Missouri Botanical Garden, v. 88, n. 3, p. 373-457. 2001.

\section{GRASS PHYLOGENY WORKING GROUP II} (GPWG II). New grass phylogeny resolves deep evolutionary relationships and discovers C4 origins. New Phytologist, v. 193, p. 304-312. 2012.

GRODZICKER, T.; WILLIAMS, J.; SHARP, P.; SAMBROOK, J. Physical mapping of temperature sensitive mutations of adenoviruses. Cold Spring Harbor Symposia on Quantitative Biology, v. 39, p. 439-446. 1974.

GUERRA, M. Introdução à citogenética geral. Rio de Janeiro: Guanabara, 1988. 142 p.

GUERRA, M. A situação da citotaxonomia de Angiospermas nos trópicos e, em particular, no Brasil. Acta Botanica Brasilica, v. 4, n. 2, p. 75-86. 1990.

GUERRA, M. Chromosome numbers in plant cytotaxonomy: concepts and implications. Cytogenetic and Genome Research, v. 120, n. 3-4, p. 339-250. 2008.

GUERRA, M. P; NODARI, R. O. Biodiversidade: aspectos biológicos, geográficos, legais e éticos. In: SIMÕES, C. M. O et al. Farmacognosia: da planta ao medicamento. 5. ed. Porto Alegre/Florianópolis: UFRGS/ UFSC, 2003. p. 13-28.

GUPTA, M.; CHYI, Y-S.; ROMERO-SEVERSON, J.; OWEN, J. L. Amplification of DNA markers from evolutionarily diverse genomes using single primers of simple-sequence repeats. Theoretical and Applied Genetics, v. 89, p. 998-1006. 1994.

GUPTA, P.; VARSHNEY, R.; SHARMA, P.; RAMESH, B. Molecular markers and their applications in wheat breeding. Plant Breeding, v. 118, p. 369-390. 1999.

HANNAN, G. L.; ORICK, M. Isozyme diversity in Iris cristata and the threatened glacial endemic Iris lacustris (Iridaceae). American Journal of Botany, v. 87, p. 293-301. 2000.

HOLSINGER, K. E.; LEWIS, P. O.; DEY, D. K. A Bayesian approach to inferring population structure from dominant markers. Molecular Ecology, v. 11, p. 1157-1164. 2002.

JEFFREYS, A. J.; WILSON, V.; THEIN, S. L. Hypervariable 'minisatellite' regions in human
DNA. Nature, v. 314, p. 67-73. 1985.

KARST, L.; WILSON, C. A. Phylogeny of the New World genus Sisyrinchium (Iridaceae) based on analyses of plastid and nuclear DNA sequence data. Systematic Botany, v. 37, n. 1, p. 87-95. 2012.

KENTON, A.; DICKIE, J. B.; LANGTON, D. H.; BENNETT, M. D. Nuclear DNA amount and karyotype symmetry in Cypella and Hesperoxiphion (Tigridieae: Iridaceae). Evolutionary Trends in Plants, v. 4, p. 59-69. 1990.

KENTON, A. Y.; RUDALL, P. J.; JOHNSON, A. R. Genome size variation in Sisyrinchium L. (Iridaceae) and its relationship to phenotype and habitat. Botanical Gazette, v. 147, p. 342-354. 1986.

LEITCH, I. J.; BEAULIEU, J. M.; CHASE, M. W.; LEITCH, A. R.; FAY, M. F. Genome size dynamics and evolution in Monocots. Journal of Botany, v. 2010, p.1-18. 2010.

LEITCH, I. J.; BENNETT, M. D. Polyploidy in angiosperms. Trends in Plant Science, v. 2, n. 12, p. 470-476. 1997.

LEITCH, I. J.; CHASE, M. W.; BENNETT, M. D. Phylogenetic analysis of DNA C-values provides evidence for a small ancestral genome size in flowering plants. Annals of Botany, v. 82, p. 85-94. 1998.

LEVIN, D. A.; FUNDERBURG, S. W. Genome size in angiosperms: temperate versus tropical species. The American Naturalist, v. 144, n. 6, p. 784-795. 1979.

LEVY, A. A.; FELDMAN, M. The impact of polyploidy on grass genome evolution. Plant Physiology, v. 130, p. 1587-1593. 2002.

LINN, S.; ARBER, W. In vitro restriction of phage $\mathrm{fd}$ replicative form. Proceedings of the National Academy of Sciences of the United States of America, v. 59, p. 1300-1306. 1968.

LITT, M.; LUTTY, J.A. A hypervariable microsatellite revealed by in vitro amplification of a dinucleotide repeat within the cardiac muscle actin gene. American Journal of Human Genetics, v. 44, n. 3, p. 397-401. 1989.

LOVO, J.; WINKWORTH, R. C.; MELLO-SILVA, R. New insights into Trimezieae (Iridaceae) phylogeny: what do molecular data tell us? Annals of Botany, v. 110, n. 3, p. 689-702. 2012. 
LYNCH, M.; MILLIGAN, B. G. Analysis of population genetic structure with RAPD markers. Molecular Ecology, v. 3, p. 91-99. 1994.

MASTERSON, J. Stomatal size in fossil plants: evidence for polyploidy in majority of angiosperms. Science, v. 264, p. 421-423. 1994.

MATHEWS, S.; SPANGLER, R. E.; MASONGAMER, R. I.; KELLOGG, E. A. Phylogeny of Andropogoneae inferred from phytochrome B, GBSSI, and NDHF. International Journal of Plant Science, v. 163, n. 3, p. 441-450. 2002.

MATZKE, M. A.; MATZKE, A. J. M. Polyploidy and transposons. Trends in Ecology and Evolution, v. 13, n. 6, p. 241. 1998.

MAYROSE, I.; BARKER, M. S.; OTTO, S. P. Probabilistic models of chromosome number evolution and the inference of polyploidy. Systematic Biology, v. 59, n. 2, p. 132-144. 2010.

MESELSON, M. R.; YUAN, R. DNA restriction enzyme from E. coli. Nature, v. 217, p. 1110-1114. 1968.

MILACH, S. C. K. Marcadores de DNA. Biotecnologia Ciência e Desenvolvimento, n. 5, p. 14-17. 1998.

MORAGA, A. R.; TRAPERO-MOZOS, A.; GÓMEZGÓMEZ, L.; AHRAZEM, O. Intersimple sequence repeat markers for molecular characterization of Crocus cartwrightianus cv. albus. Industrial Crops and Products, v. 32, p. 47-151. 2010.

MORENO, N.; LAS PEÑAS, M. L.; BERNARDELLO, G.; ROITMAN, G. Cytogenetic studies in Herbertia Sw. (Iridaceae). Caryologia, v. 62, p. 37-42. 2009.

NYBOM, H. Comparison of different nuclear DNA markers for estimating intraspecific genetic diversity in plants. Molecular Ecology, v. 13, n. 5, p. 1143-1155. 2004.

OHRI, D. Genome size variation and plant systematics. Annals of Botany, v. 82, p. 75-83. 1998.

OTTO, S. P. The evolutionary consequences of polyploidy. Cell, v. 131, p. 452-462. 2007.

PAGLIARINI, M. S.; CARRARO, L. R.; FREITAS, P. M.; ADAMOWSKI, E. V.; BATISTA, L. A. R.; VALLS, J. F. M. Cytogenetic characterization of Brazilian Paspalum accessions. Hereditas, v. 135, p. 27-34. 2001.
PETERSEN, G.; SEBERG, O.; THORSØE, S.; JØRGENSEN, T.; MATHEW, B. A phylogeny of the genus Crocus (Iridaceae) based on sequence data from five plastid regions. Taxon, v. 57, p. 487-499. 2008.

PINTO, L. R.; VIEIRA, M. L. C.; SOUZA, A.P.; SOUZA JÚNIOR, C. L. Isoenzimas e Microssatélites em Plantas. Biotecnologia Ciência \& Desenvolvimento, n. 20, p. 16-19. 2001.

POZZOBON, M. T.; VALLS, J. F. M. Chromosome number in germplasm accessions of Paspalum notatum (Gramineae). Brazilian Journal of Genetics, v. 20, n.1, p. 29-34. 1997.

POZZOBON, M. T.; VALLS, J. F. M. Cytogeography and variation of stomatal size of Paspalum glaucescens (Gramineae; Paniceae) in Southern Brazil. Euphytica, v. 116, p. 251-256. 2000.

POZZOBON, M. T.; VALLS, J. F. M.; SANTOS, S. Contagens cromossômicas em espécies brasileiras de Paspalum L. (Gramineae). Acta Botanica Brasilica, v. 14, n. 2, p. 151-162. 2000.

QUARIN, C. L.; BURSON, B. L. Cytogenetic relations among Paspalum notatum var. saurae, P. pumilum, $P$. indecorum and P. vaginatum. Botanical Gazette, v. 144, n. 3, p. 433-438. 1983.

RAMSEY, J.; SCHEMSKE, D. W. Neopoliploidy in flowering plants. Annual Review of Ecology and Systematics, v. 33, p. 589-639. 2002.

RANJAN, P.; BHAT, K. V.; MISRA, R. L.; SINGH, S. K.; RANJAN, J. K. Genetic relationships of gladiolus cultivars inferred from fluorescence based AFLP markers. Scientia Horticulturae, v. 123, p. 562-567. 2010.

RAVEN, P. The bases of angiosperm phylogeny: Cytology. Annals of the Missouri Botanical Garden, v. 62, p. 724-764. 1975.

REEVES, G.; CHASE, M. W.; GOLDBLATT, P.; RUDALL, P. J.; FAY, M. F.; COX, A. V.; LEJEUNE, B.; SOUZA-CHIES, T. A phylogenetic analysis of Iridaceae based on four plastid sequence regions: trnL intron, trnL-F spacer, rps 4 and rbcL. American Journal of Botany, v. 88, p. 2074-2087. 2001.

RODRIGUEZ, A.; SYTSMA, K. Phylogeny of the 'tiger-flower group (Tigiridieae: Iridaceae): molecular and morphological evidence. In: COLUMBUS, J. T.; FRIAR, E. A.; PORTER, J. M.; PRINCE, L. M.; SIMPSON, M. G. (eds). Monocots: 
comparative biology and evolution. vol. 1 . Claremont: Rancho Santa Ana Botanical Garden, 2006. p. 412-424.

ROITMAN, G.; CASTILLO, A. A new species, Herbertia crosae (Iridaceae), from Uruguay. Brittonia, v. 56, p. 361-364. 2004.

RYMER, P. D.; MANNING, J. C.; GOLDBLATT, P.; POWELL, M. P.; SAVOLAINEN, V. Evidence of recent and continuous speciation in a biodiversity hotspot: a population genetic approach in southern African gladioli (Gladiolus; Iridaceae). Molecular Ecology, v. 19, p. 4765-4782. 2010.

SAIKI, R.K.; GELFAND, D.H.; STOFFEL, S.; SCHARF, S.J.; HIGUCHI, R.; HORN, G.T.; MULLIS, K.B.; ERLICH, H.A. Primer-directed enzymatic amplification of DNA with a thermostable DNA polymerase. Science, v. 239, p. 487-491. 1988.

SÁNCHEZ-KEN, J. G.; CLARK, L. G. Phylogeny and a new tribal classification of the Panicoideae s.l. (Poaceae) based on plastid and nuclear sequence and structural data. American Journal of Botany, $\mathrm{v}$. 97, n. 10, p. 1732-1748. 2010.

SCHIFINO-WITTMANN, M. T. Determinação da quantidade de DNA nuclear em plantas. Ciência Rural, v. 31, n. 5, p. 897-902. 2001.

SOLFERINI, V. N.; SCHEEPMAKER, D. S. Polimorfismo de Isoenzimas. In: MATIOLI, S. R. Biologia Molecular e Evolução. Ribeirão Preto: Holos, 2001. p. 147-142.

SOLTIS, D. E.; SOLTIS, P. S. The dynamic nature of polyploid genomes, Proceedings of the National Academy of Sciences of the United States of America, v. 92, p. 8089-8091. 1995.

SOLTIS, D. E.; SOLTIS, P. S. Polyploidy: recurrent formation and genome evolution. Trends in Ecology and Evolution, v. 14, p. 348-352. 1999.

SOLTIS, D. E.; ALBERT, V. A.; LEEBENS-MACK, J.; BELL, C. D.; PATERSON, A. H.; ZHENG, C.; SANKOFF, D.; DEPAMPHILIS, C. W.; WALL, P. K.; SOLTIS, P. S. Polyploidy and angiosperm diversification. American Journal of Botany, v. 96, n. 1, p. 336-348. 2009.

SOLTIS, D. E.; SOLTIS, P. S.; BENENT, M. D.; LEITCH, I. J. A. Evolution of genome size in the angiosperms. American Journal of Botany, v. 90, n. 11, p. 1596-1603. 2003.
SOUZA-CHIES, T. T.; BITTAR, G.; NADOT, S.;

CARTER, L.; BESIN, E.; LEJEUNE, B. Phylogenetic analysis of Iridaceae with parsimony and distance methods using the plastid gene rps4. Plant Systematics and Evolution, v. 204, p. 109-123. 1997.

SOUZA-CHIES, T. T.; ESSI, L.; RUA, G.; VALLS, J. F. M. e MIZ, R. A preliminary approach to the phylogeny of the genus Paspalum (Poaceae). Genetica, v. 126, p. 15-32. 2006.

\section{SOUZA-CHIES, T. T.; KALTCHUK DOS SANTOS,}

E.; EGGERS, L.; FLORES, A.M.; STIEHL-ALVES, E. M.; FACHINETTO, J.; LUSTOSA, J.; CORRÊA, L.B.; TACUATIÁ, L. O.; PICCOLI, P.; MIZ, R. B. Studies on diversity and evolution of Iridaceae species in southern Brazil. Genetics and Molecular Biology, v. 35, n. 4, p. 1027-1035. 2012.

STEBBINS, G. L. Chromosome variation and evolution. Science, v. 152, p. 1463-1469. 1966.

TACUATIÁ, L. O.; EGGERS, L.; KALTCHUKSANTOS, E.; SOUZA-CHIES, T. T. Population genetic structure of Sisyrinchium micranthum Cav. (Iridaceae) in Itapuã State Park, Southern Brazil. Genetics and Molecular Biology, v. 35, n. 1, p. 99105. 2012a.

TACUATIÁ, L. O.; SOUZA-CHIES, T. T.; FLORES, A. M.; EGGERS, L.; SILJAK- YAKOVLEV, S.; KALTCHUK-SANTOS, E. Cytogenetic and molecular characterization of morphologically variable Sisyrinchium micranthum (Iridaceae) in southern Brazil. Botanical Journal of the Linnean Society, v. 169, p. 350-364. 2012b.

TAKAYAMA, S. Y.; FREITAS, P. M.; PAGLIARINI, M. S.; BATISTA, L. A. R. Chromosome number in germplasm accessions of Paspalum (Plicatula group) from different regions in Brazil. Euphytica, v. 99, p. 89-94. 1998.

VAN DE PEER, Y.; MAERE, S.; MEYER, A. The evolutionary significance of ancient genome duplications. Nature Reviews Genetics, v. 10, n. 10, p. 725-732. 2009.

VOS, P.; HOGERS, R.; BLEEKER, M.; REIJANS, M.; VAN DE LEE, T.; HORNES, M.; FRIJTERS, A.; POT, J.; PELEMAN, J.; KUIPERVOS, M. AFLP: a new technique for DNA fingerprinting. Nucleic Acids Research, v. 23, p. 4407-4414. 1995.

WILLIAMS, J. G. K.; KUBELIK, A. R.; LIVAK, K. J.; RAFALSKI, A. J. A.; TINGEY, S. V. DNA polymorphisms amplified by arbitrary primers are 
useful as genetic markers. Nucleic Acids Research, v. 18, p. 6531-6535. 1990.

WILSON, C. A. Phylogenetic relationships in Iris series Californicae based on ITS sequences of nuclear ribosomal DNA. Systematic Botany, v. 28, p. 39-46. 2003.

WILSON, C. A. Phylogeny of Iris based on chloroplast matK gene and trnK intron sequence data.

Molecular Phylogenetics and Evolution, v. 33, p. 402-412. 2004.

WILSON, C. A. Subgeneric classification in Iris reexamined using chloroplast sequence data. Taxon, v. 60, p. 27-35. 2011.

WINGE, H. Studies on cytotaxonomy and polymorphism of the genus Alophia (Iridaceae). Revista Brasileira de Biologia, v. 19, p. 195-201. 1959.

WOLFF, K.; MORGAN-RICHARDS, M. PCR markers distinguish Plantago major subspecies. Theoretical and Applied Genetics, v. 96, p. 282-286. 1998.

WOOD, T. E.; TAKEBAYASHI, N.; BARKER, M. S.; MAYROSE, I.; GREENSPOON, P. B.; RIESEBERG, L. H. The frequency of polyploid speciation in vascular plants. Proceedings of the National Academy of Sciences of the United States of America, v. 106, n. 33, p. 13875-13879. 2009.

WRÓBLEWSKA, A.; BRZOSKO, E.; CZARNECKA, B. E.; NOWOSIELSKI, J. A. High levels of genetic diversity in populations of Iris aphylla L. (Iridaceae), an endangered species in Poland. Botanical Journal of the Linnean Society, v. 142, p. 65-72. 2003.

ZIETKIEWICZ, E.; RAFALSKI, A.; LABUDA, D.

Genome fingerprinting by simple sequence repeat (SSR)-anchored polymerase chain reaction amplification. Genome, v. 20, p. 176-183. 1994. 